\title{
Synthesis of L-carnosine and its applications in biomedical fields
}

\author{
Maryam Khosravi a , Rahmatollah Rahimi ${ }^{\text {a* }}$, Ebrahim Safavi ${ }^{\text {b }}$ \\ aDepartment of Chemistry, Iran University of Science and Technology, Narmak, Tehran. \\ ${ }^{b}$ Member Of The World Society Of The Anti-Aging Medicine and International Hormone Society. Niavaran, \\ Tehran, Iran.
}

*Corresponding author. Tel: + 9821 77240290; fax: + 982177491204.

E-mail address: Rahimi_rah@iust.ac.ir

\begin{abstract}
Chelation therapy is the administration of chelating agents to remove heavy metals from the body. Chelation therapy has a long history of use in clinical toxicology. For the most common forms of heavy metal intoxication - lead, arsenic, or mercury. A number of chelating agents are available are ethylenediaminetetraacetate (EDTA), dimercaptosuccinic acid (DMSA), 2,3-dimercapto-1-propanesulfonic acid (DMPS), alpha lipoic acid (ALA) and carnosine. They used in conventional and alternative medicine. In this work synthesize of carnosine has been studied. Carnosine (beta-alanyl-L-histidine) is a dipeptide of the amino acids beta-alanine and histidine. Carnosine is found naturally in healthy muscles, heart, brain, liver, kidneys and other tissues.

$\mathrm{N}$-Protected amino acids are important intermediates in organic synthesis. The use of N-phthalylamino acids as coupling agents in the synthesis of peptides has been studied by several groups of investigators. Hydrolysis of the phthalyl group with hydrazine at room temperature affords a direct synthesis of L-Carnosine. The molecular structures of the compounds were definite by using UV-Vis and FT-IR spectroscopy.
\end{abstract}

Keywords: Chelation therapy, L-Carnosine, Phthalyl- $\beta$-alanyl, Histidine.

\section{Introduction}

Lead, mercury, and arsenic serve no function in the human body. If they accumulate in large enough amounts, they cause poisoning. Other metals which are essential to human function can become toxic if they accumulate in large amounts examples include iron and copper. Effects differ according to the metal involved, whether it is introduced into the body by ingestion, inhalation, or skin contact, and the victim people with very high levels of these heavy metals are treated with drugs, called "chelators". These medicines bind to the metals in the blood stream; this metal-chelator compound is then eliminated in the urine. Other uses include treating damaged arteries (atherosclerosis) by removing calcium from arterial plaques, curing or improving symptoms of autism, preventing or curing neurodegenerative conditions such as alzheimer's disease, kidney dysfunction, eye disorder, thyroid, arthritis and etc. [1]. Carnosine, $\beta$-alanyl-L-histidine, is a naturally occurring dipeptide that in humans is preferentially localized in skeletal muscles and brain. Carnosine can display a variety of physiological roles, including that of a cytosolic buffering agent, that of a regulator of content of transition metal ions in biological fluids and tissues owing to its ability to form complexes with these ions and that of a regulator of macrophage function [2-5]. It is a potent scavenger of both reactive oxygen species (ROS) and reactive nitrogen species (RNS) which induce peroxidation of unsaturated lipids present in membranes as well as of toxic reactive $\alpha, \beta$-unsaturated aldehydes deriving from this oxidation [6-9]. Acrolein, 4-hydroxytrans-2,3-nonenal (HNE), and malondialdehyde are examples of such products. They are potent bifunctional electrophiles able to bind nucleophilic centers present in both DNA and proteins. In addition, the second electrophilic center may undergo additional attack affording protein-protein and DNA-protein cross-linking. The final result is an amplification of the cellular damage induced by oxidative attack on membranes. Another source of cellular damage is the glycation of proteins, namely the process where by reducing sugars react with protein amino groups generating Schiff's bases. These latter products, in turn, can afford advanced glycation end products (AGEs) able to incorporate additional proteins through stable cross-links [10]. AGEs are toxic for those cells that are able to recognize them. Carnosine is capable of protecting proteins against glycation and reacting with protein carbonyl groups to form carboxylated proteins [11-14]. Because ROS, RNS, lipidic oxidation, and glycation products may contribute to the development of many neurodegenerative and cardiovascular diseases, today there is a great interest in carnosine and related structures as potential therapeutic tools. Interest in amino acids has 
increased enormously during recent years mainly because of the many new uses which have been found for these compounds in the nutritional and medicinal fields [15]. The phthalyl method for the preparation of carnosine was investigated since N-phthalyl- $\beta$-alanine could be prepared in good yields from phthalimide [16].

\section{Experimental}

Chemicals. $\beta$-alanine, L-histidine hydrochloride monohydrate, phthalic anhydride, glacial acetic acid, benzene, sodium azide, Petroleum ether, dioxane, ethanol, triethylamine, phenylhydrazine, methyl ethyl ketone were obtained from Merck Chemical Co.

The infrared spectra in the range $400-4000 \mathrm{~cm}^{-1}$ were recorded on a Shimadzu FTIR-8400S spectrophotometer. UV spectrophotometer (Shimadzu UV-1700) was used.

The phthalyl group has been utilized in a variety of cases as a masking group in the preparation of amino acids [17.] the stepwise preparation of carnosine included:

In the first stage $\beta$-Alanine $(3.2381 \mathrm{~g})$, and phthalic anhydride $(3.854 \mathrm{~g})$ were heated under reflux in glacial acetic acid $(32.5 \mathrm{ml})$ for $3 \mathrm{~h}$ (bath temperature $=118^{\circ} \mathrm{C}$ ). The acetic acid was evaporated under vacuum. Water $(7 \mathrm{ml})$ was added to the residue and the mixture was refluxed for 1 hour. After cooling, the resulting mixture was extracted with ether-water $(1: 4)$. The precipitated solid was filtered and dried under vacuum to give white crystals of the phtalyl $\beta$-alanine. Then substitute the phtalyl $\beta$-alanine with oxalyl chloride $(1.75 \mathrm{ml})$ and chenged it to phthalyl- $\beta$-alanyl chloride [18]. the product chenged to phthalyl- $\beta$-alanyl azide. In this step phthalyl- $\beta$-alanyl Azide was obtaind, dissolved in $25 \mathrm{ml}$. of dioxane, and the resulting solution poured into the aqueous histidine solution. The mixture was allowed to stand in the refrigerator overnight. The reaction mixture was neutralized with $(4.7 \mathrm{ml})$ of sulfuric acid. The resulting mixture was filtered and concentrated to dryness at $50^{\circ}$ under reduced pressure. The residue was extracted with boiling methanol, and the combined filtrates were placed in the refrigerator. A white crystalline solid was obtained that name is phthalyl carnosine. The procedure used for the removal of the phthalyl group is, to $(1.78 \mathrm{~g})$ of phthalylcarnosine there was added $25 \mathrm{ml}$ ethyl alcohol, $(0.5 \mathrm{~g})$ of triethylamine and $(1.55 \mathrm{~g})$ of phenylhydrazine. The mixture was refluxed for three hours. At the completion of the heating period, the clear yellow solution was cooled, and acidified with $(1 \mathrm{~g})$ of glacial acetic acid, and the mixture poured into $(80 \mathrm{ml})$ of methyl ethyl ketone. An amorphous precipitate was obtained which was dissolved in $(5 \mathrm{ml})$ of water and reprecipitated by the addition of $(75 \mathrm{ml})$ ethyl alcohol, after recrystallization from aqueous ethyl alcohol, carnosine was obtained (80\%) (Fig. 1) [16].

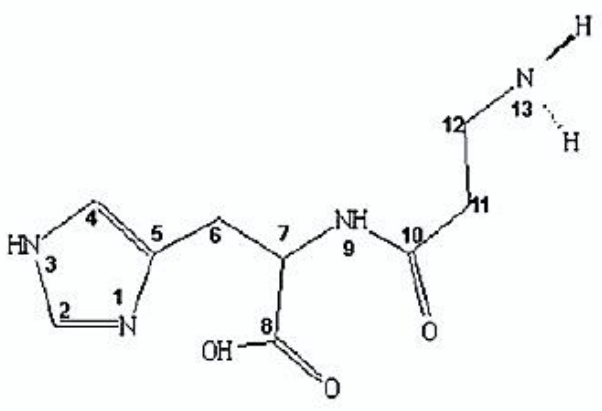

Fig. 1. structure of carnosine

\section{Results and Discussion}

\subsection{Infrared Spectroscopy}

The infrared vibrational spectra provided an abundance of structural information of carnosine (Fig. 2) and a summary of the infrared vibrational assignments is given in Table1 [19]. 


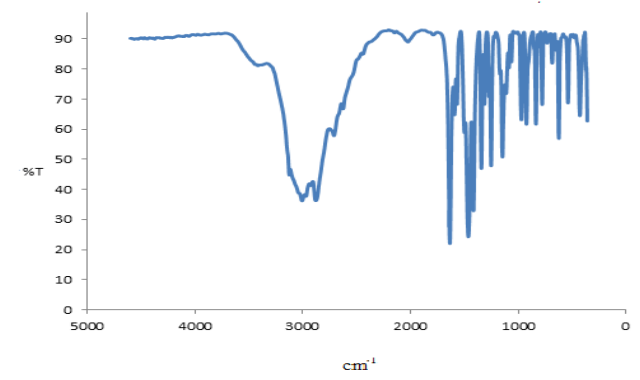

Fig. 2. FT-IR Spectrum of L-carnosine

Table 1. Summary of the infrared vibrational assignments

\begin{tabular}{|c|c|}
\hline Assignments & Carnosine $v\left(\mathrm{~cm}^{-1}\right)$ \\
\hline $\mathrm{v}_{\mathrm{a}}\left(\mathrm{NH}_{2}\right)$ & $3129-3444$ \\
\hline Amide & 1635 \\
\hline Imidazole $\mathrm{v}\left(\mathrm{C}_{4}=\mathrm{C}_{5}\right)$ & 1563 \\
\hline Imidazole Stretching & 1463 \\
\hline$\delta(\mathrm{N}-\mathrm{H})$ & 1432 \\
\hline $\mathrm{v}_{\mathrm{s}}\left(\mathrm{COO}^{-}\right)$ & 1415 \\
\hline $\mathrm{v}(\mathrm{C}-\mathrm{N})$ & 1342 \\
\hline Imidazole $\mathrm{v}(\mathrm{NCN})$ & 1251 \\
\hline Imidazole $\delta(\mathrm{N}-\mathrm{H})$ & 1145 \\
\hline
\end{tabular}

$\mathrm{v}=$ stretching; $\mathrm{v}_{\mathrm{a}}=$ asymmetric stretching; $\mathrm{v}_{\mathrm{s}}=$ symmetric stretching; $\delta=$ in-plane bending

\section{2. Electronic Spectroscopy}

The UV-Vis absorbance spectra of carnosine, with absorbance bands observed at $266 \mathrm{~nm}$ and $213 \mathrm{~nm}$ which can be assigned to $n-\pi^{*}$ and $\pi-\pi^{*}$ of synthesized carnosine [19].

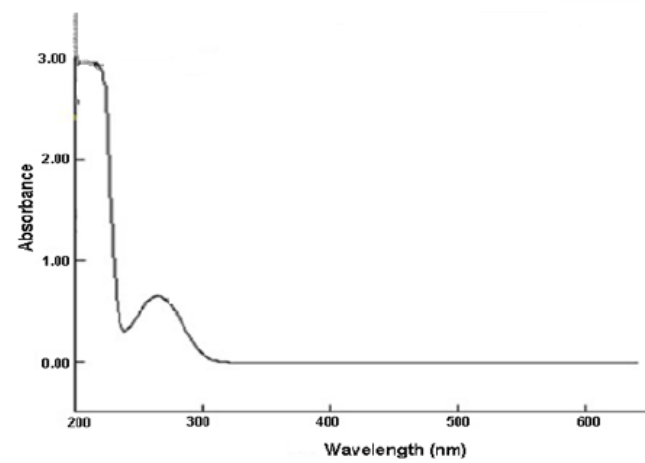

Fig. 3. UV-Vis Spectrum of L-carnosine

\section{Conclusions}

In the present work, carnosine was synthesized that has a lot of beneficial properties and its applications in biomedical fields are continuously growing (with yield of $80 \%$ ). Carnosine may have a more fundamental role in cellular maintenance, since it is well established that the efficiency of maintenance in mammalian species is correlated with lifespan. 


\section{References}

(1) Kosnett MJ. Chelation for heavy metals (arsenic, lead, and mercury): protective or perilous, Clin Pharm \& Therapeutics. 2010, 88, 412-415.

(2) Boldyrev, A. A. Carnosine and Oxidative Stress in Cells and Tissues, Nova Science Publisher, New York, 2006.

(3) Hipkiss, A. R. Carnosine, a protective, anti-ageing peptide, J. Biochem. Cell Biol. 1998, 30, 863-868.

(4) Hipkiss, A. R.; Preston, J. E.; Himsworth, D. T. M.; Worthington, V. C.; Keown, M.; Michaelis, J.; Lawrence, J.; Mateen, A.; Allende, L.; Eagles, P. A. M.; Abbott, N. J. Pluripotent Protective Effects of Carnosine, A Naturally Occuring Dipeptide. Ann. N.Y. Acad. Sci. 1998, 854, 37-53.

(5) Stvolinsky, S. L.; Dobrota, D. Anti-ischemic Activity of Carnosine. Biochemistry (Moscow) 2000, 65, 9981005.

(6) Hipkiss, A. R. Could Carnosine or Related Structures Suppress Alzheimer Disease, J. Alzheimer's Dis. 2007, 11, 229-240and references therein.

(7) Xu, G.; Aldini G, Carini M, Beretta G, Bradamante S, Facino RM. Carnosine is a quencher of 4-hydroxy-nonenal: through what mechanism of reaction, Biochem Biophys Res Commun. 2002 Nov $15 ; 298(5): 699-706$.

(8) Liu, Y.; Sayre, L. M. Carnosine Inhibits (E)-4-Hydroxy-2- nonenal-Induced Protein Cross-Linking: Structural Characterization of Carnosine-HNE Adducts. Chem. Res. Toxicol. 2003, 16, 1589-1597.

(9) Guiotto, A.; Calderan, A.; Ruzza, P.; Borin, G. Carnosine and Carnosine-Related Antioxidants: A Review. Curr. Med. Chem.2005, 12, 2293-2315.

(10) Bierhaus, A.; Hofman, M.; Ziegler, R.; Nawroth, P. P. AGEs and their interactions with AGE receptors in vascular disease and diabetes mellitus. 1. AGE concept. Cardiovasc. Res. 1998, 37, 586-600.

(11) Hipkiss, A. R.; Michaelis, J.; Syrris, P. Non-enzymatic glycosation of the dipeptide L-carnosine, a potential anti-protein-cross-linking agent. FEBS Lett. 1995, 371, 81-85.

(12) Hipkiss, A. R.; Brownson, C. A possible new role for the anti-ageing peptide carnosine. Cell. Mol. Life Sci. 2000, 57, 747-753.

(13) Hobart, L.; Seibel, I.; Yeargans., G. S.; Seidler, N. W. Anti-crosslinking properties of carnosine: significance of histidine. Life Sci. 2004, 75, 1379-1389.

(14) Massimo Bertinaria, Barbara Rolando, Marta Giorgis, Gabriele Montanaro, Stefano Guglielmo, M. Federica Buonsanti, Valentina Carabelli, Daniela Gavello, Pier Giuseppe Daniele, Roberta Fruttero, and Alberto Gasco. Synthesis, Physicochemical Characterization, and Biological Activities of New Carnosine Derivatives Stable in Human Serum as Potential Neuroprotective Agents. J. Med. Chem. 2011, 54, 611-621.

(16) Harryk Roll, Henryh Oberman, J. American Chemical Society, 75, (1953), 2511.

(17) John C. Sheeha, Victors. Fran, Biochemistry (Moscow), 71, 1949, 1856-1861

(18) Radia Mahboub, J. Chem. Sci. 7(1), 2009, 28-36.

(19) Michael Lee Branham 1, Parvesh Singh, Krishna Bisetty, Myalo Sabela, Thirumala Govender, Molecules, 16, 2011, 10269-10291.

(20) R. Holliday, G. A. McFarland, Biochemistry (Moscow), 65( 7), 2000, 843-848. 